\title{
Survey of damage to schools and the initial stage of recovery after the 2013 Typhoon Haiyan, Leyte Province, the Philippines
}

\author{
C. J. Yi, M. Yasuda, A. Suppasri \& F. Imamura \\ International Research Institute of Disaster Science, \\ Tohoku University, Japan
}

\begin{abstract}
On 8th November 2013, the super Typhoon Haiyan (Yolanda) struck the Eastern Visayas Region of the Philippines with wind speeds of $315 \mathrm{~km} / \mathrm{h}$. As a result, 14.1 million people were affected, with the estimated number of fatalities reaching 6,201 and more than 1,785 missing. The municipality of Tanauan estimated the damage cost of 34 elementary and primary schools to be 91,419,944 PHP (as of February 2014). The Face-to-Face Method survey was employed at 11 elementary schools near the coast in the cities of Tanauan and Palo to understand damage to the school buildings and their recovery process. School roofs, windows, doors, and ceilings were heavily damaged. For example, Santa Cruz primary school in Tanauan was completely destroyed by a storm surge that reached $3.8 \mathrm{~m}$ in height. Most schools reopened within two months for the purpose of providing care for students rather than providing education. UNICEF and international NGOs provided school supplies, foods, sanitary goods, and building tools; a Taiwanese NGO, the Tzu Chi Foundation, built temporary classrooms in schoolyards. Damaged schools were repaired by ARAW, South Korea's biggest and longest international campaign for humanitarian assistance between January 3 and November 27, 2014. The students need to be structurally educated and the program materials and necessities prepared so that when another disaster strikes, the younger generations of today can face the disaster and overcome the challenges by strong will or with structured systems and tools. The schools in each community need to develop a suitable disaster risk reduction strategy and resilience program.

Keywords: Typhoon Haiyan (Yolanda), school damage, disaster recovery, NGO.
\end{abstract}




\section{Introduction}

The super Typhoon Haiyan (Yolanda) struck the Eastern Visayas Region of the Philippines with wind speeds of $315 \mathrm{~km} / \mathrm{h}$ on 8th November 2013. Approximately 14.1 million people had been affected, with estimated fatalities reaching 6,201 and more than 1,785 missing, according to the United Nations (UN) [1]. The survey team at the International Research Institute of Disaster Science (IRIDeS) of Tohoku University was accredited to investigate school damage from storm surge and strong winds from May 28 to June 02, 2014, and a face-to-face survey was conducted in 18 elementary schools in the Tanauan area. The location of Tanauan is shown in fig.1. According to the 2012 statistics of the municipality of Tanauan, the population of Tanauan was 50,907, with 9,624 households in 54 barangays, the smallest administrative district. As of February 6,2014 in the municipality of Tanauan, 822 people were killed in 32 barangays and 35 people are still missing due to Typhoon Haiyan. The overall damage to the San Loque area in Tanauan are shown in fig. 2, including the destruction of the pier of the oil company. The highway brings business to nearby Barangays, and those Barangays have large populations; naturally, elementary schools near the coast have large numbers of students. Primary schools accept only grade one and two students, and elementary schools have grades one to six. Almost every Barangay has an elementary school with its Barangay's name. However, far-inland Barangays have no school; only primary schools and/or satellite schools with small-size classes, dependent upon the population. The 2012 Tanauan municipality census estimates the population between the ages of 6 and

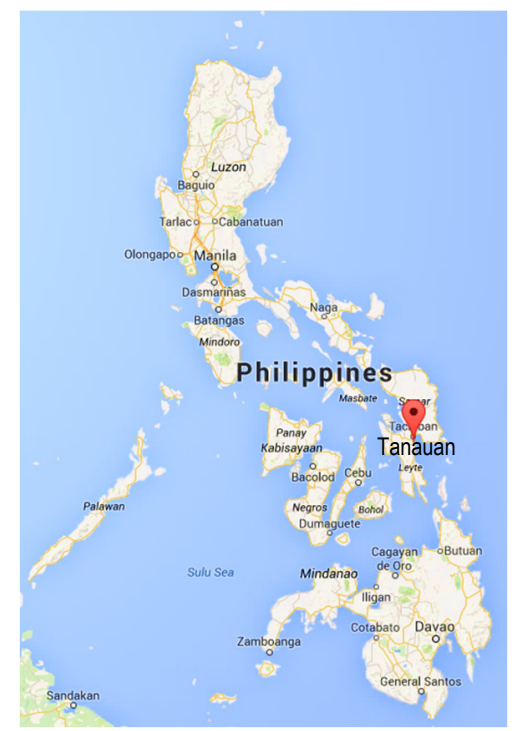

Figure 1: Location of the municipality of Tanauan, Leyte, The Philippines (Google Map). 

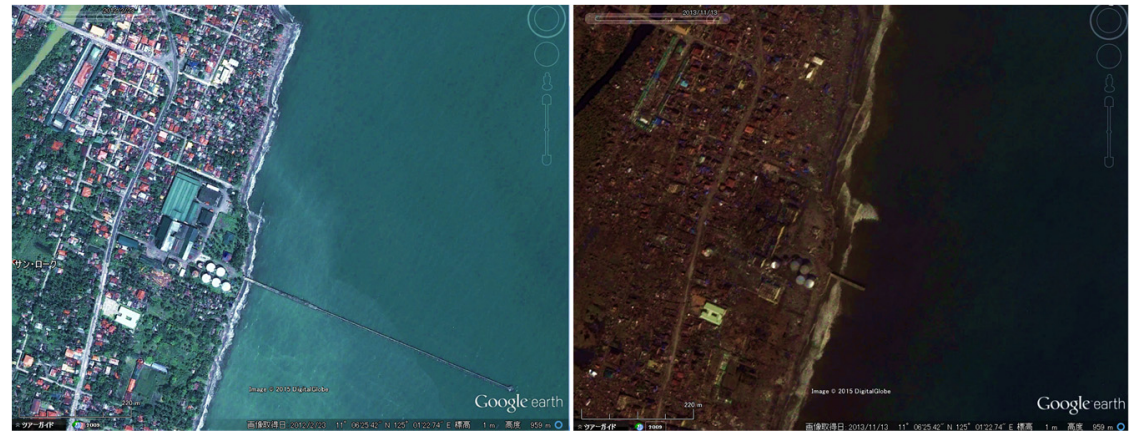

Figure 2: Google Earth image: pre- and post-Typhoon Haiyan in San Loque area in Tanauan (as of 2013/11/13 (left) and 2012/2/23 (right)).

12 numbers 7,615. The municipality of Tanauan estimated the damage cost of 34 elementary and primary schools to be over 90 million Philippines Pesos (PHP) (as of February, 2014). Schools, particularly elementary schools, are the main feature in the local community. Additionally, children are inextricably linked to the community's future, and it is necessary to explore strategies for further strengthening the linkages [2].

This study focuses on the aftermath of Typhoon Haiyan, conditions of damage to the schools, the recovery of bodies and supporting data related to students and school rebuilding. Furthermore, this study analyzes the estimation of the education service for the community, especially after the severe disaster, and focuses on the redevelopment of the community as well as how to enhance sustainable resilience based on the survey.

\section{Method}

The Face-to-Face Method survey was conducted from May 28 to June 02, 2014 on-site at 19 elementary schools in Tanauan, Palo and Tacloban to understand school building damage and conditions. The locations of surveyed schools are shown in Figure 3 with storm surge inundation areas that were created by measurement of the IRIDeS team at a different time. The area inundated with storm surge is shown in blue. Questions were developed in Japanese and translated to English. There are eight categories for the questions:

i. Physical damage to school building(s);

ii. Damage to schoolyards and school materials;

iii. Death/injury of students and/or teachers;

iv. If the parents of student(s) lost their jobs;

v. Time of school reopening;

vi. Budget to reopen the school;

vii. Who provided support to maintain the school during the aftermath;

viii. Related information: evacuation location; locations of shelters and actual use of evacuation shelter; how to decide to re-open schools and its timeline; what kind of materials were most needed, and so on. 


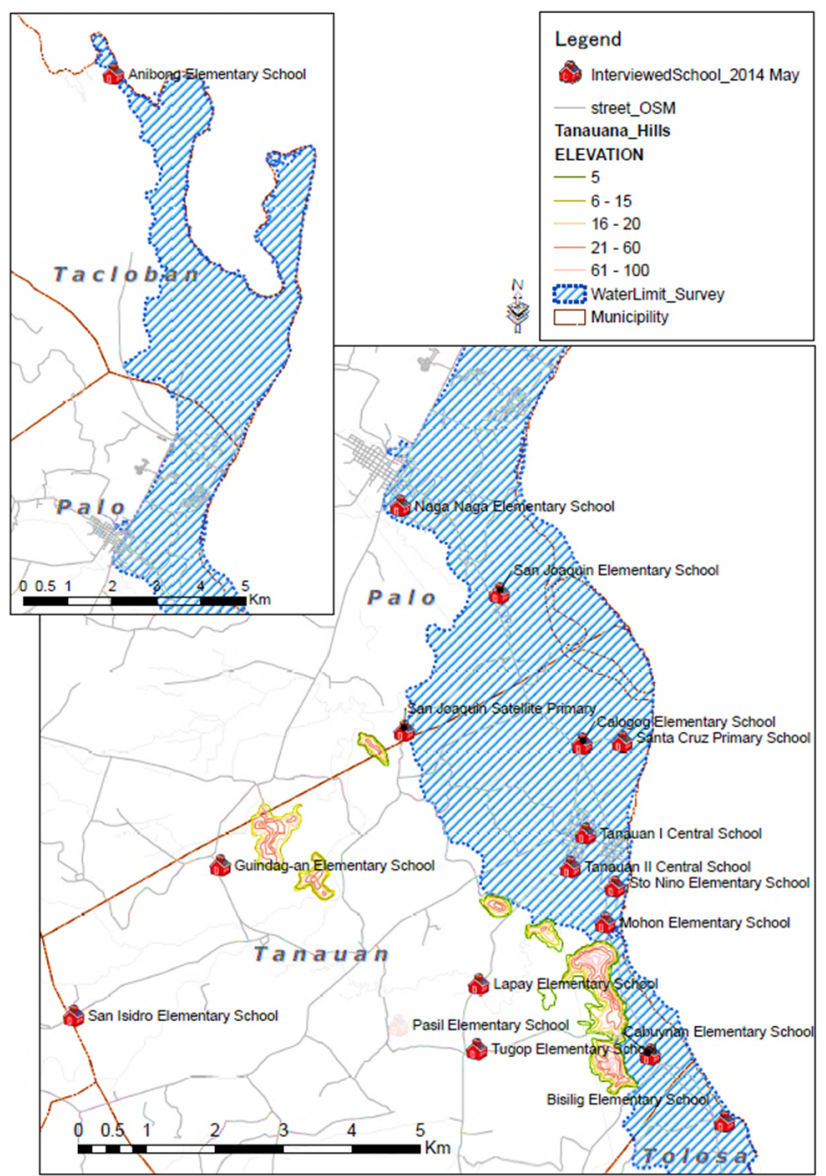

Figure 3: The location of interviewed schools.

Furthermore, the survey team also measured the height of inundation level after notification of the issue by an interviewee. The municipality of Tanauan provided the list of schools and the damage cost, detailed by roof, ceiling, doors and windows. The team followed the school list to determine the exact location with a GPS Camera that will store each photo's coordinates. The photos of schools were imported into the GIS software using the GeoTagged Photos to point tool, which creates a marker tagged with geo-coordination information.

\section{Results}

\subsection{Geographic information of schools}

The survey team visited 34 schools in total in Tanauan, Palo and Tacloban, and surveys were conducted at 19 schools, including primary schools and satellite 
schools from the coast to far west inland. Anibong elementary school in Tacloban is the only school that stands on a hill; it sustained severe wind damage, similar to the far inland schools of Tanauan. As shown in Figure 3, 11 schools are located in a flood zone by the main street, creating densely populated areas. Storm surge reached more than a maximum of $3.6 \mathrm{~km}$ from the coast, and schools located in this flooded area were devastated by both storm surge and strong winds.

\subsection{Human damage in schools}

Some schools near the coast lost their students and teachers to Typhoon Haiyan. A total of 29 students were killed among 1,109 students. Tanauan II elementary schools lost four students. On the other hand, teachers were all safe. In the San Joaquin elementary school in Palo, one teacher was killed and two children became orphans. Calogcog elementary school (Tanauan) is also located near the coast, where the storm surge reached a level of approximately $4.4 \mathrm{~m}$. In this school, among 228 students, 34 students were killed. A total of 15 students lost a family member; the teachers were all safe. Cabuynan elementary school (Tanauan) also lost 13 students among 533 students, and more than 20 students were injured. However, no teacher was killed. Cabuynan reopened in early December. Santo Niño elementary school (Tanauan) lost four students among 566 students; however, all teachers survived. Mohon elementary school is located in Tanauan approximately $2 \mathrm{~km}$ away from the coast. Unexpectedly, the storm surge reached $2.7 \mathrm{~m}$ in height, and this caused 27 student deaths out of 241 total students, as well as one retired teacher death. Naga elementary school in Palo had $2.18 \mathrm{~m}$ of storm surge, and two students and one teacher were killed.

\subsection{School building damage}

The survey team visited 34 elementary schools in Tanauan, as well as two elementary schools in Palo and one school in Tacloban to investigate school building damage. The survey period fell during summer vacation, and schools were preparing for the next semester, which would begin in a week. The team was able to learn the detailed damage conditions from principals, teachers, neighbors and Barangay chairmen/captains in 14 elementary schools in Tanauan, three elementary schools including a satellite school in Palo, and one elementary school in Tacloban. The team visited schools: Tanauan I central and Tanauan II central on May 27; San Joaquin and its satellite school in Palo and Santa Cruz, Calogcog, Cabuynan, and Santo Nino in Tanauan on May 28; Bisilig, Tugop and Lapay in Tanauan on May 29; Guindag-an and San Isidro in Tanauan on May 30; Mohon in Tanauan and Naga in Palo on May 31; Anibong in Tacloban and Canbalisara and Pasil in Tanauan on June 01, 2014.

The municipality of Tanauan provided the estimated damage cost in detail of roofs, ceilings, walls, windows and doors. However, the standard used to determine damage level was absent, and related metadata were not found. Depending on school size, every school has one to 12 buildings in a school property, and the floor size ranges from $67.50 \mathrm{~m}^{2}$ for one building (Balud 
primary school in Tanauan) to $2,140.05 \mathrm{~m}^{2}$ for nine buildings (Tanauan II central school). The range of economic loss ratio $\left(\mathrm{PHP} / \mathrm{m}^{2}\right)$ was calculated between 120 $\mathrm{PHP} / \mathrm{m}^{2}$ (Binongtoan primary school-damaged roof only) and 12,987 $\mathrm{PHP} / \mathrm{m}^{2}$ (Santa Cruz primary school experienced total destruction and was located only $406 \mathrm{~m}$ from the coast). Most of the schools required about one and a half months to two months to reopen.

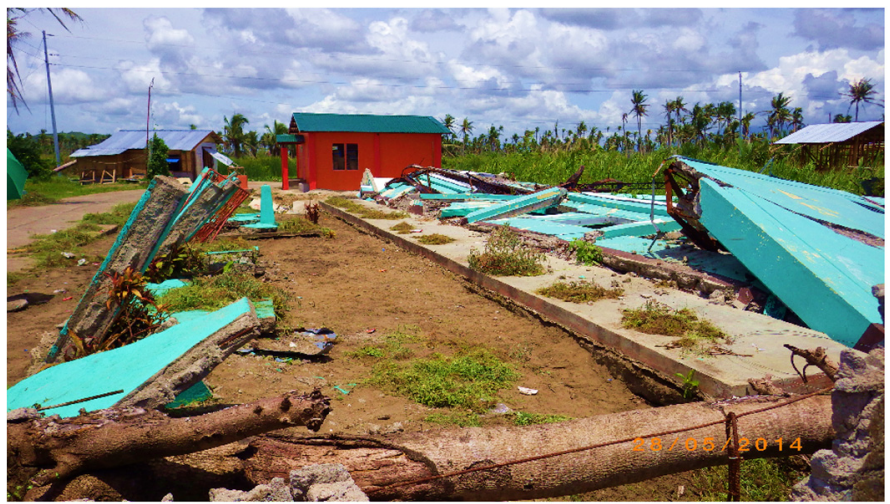

Figure 4: Santa Cruz primary school buildings were completely destroyed in the typhoon.

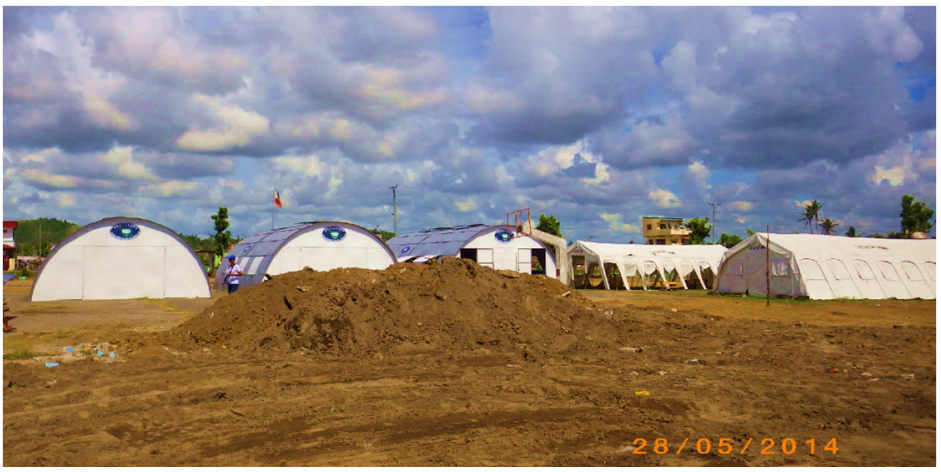

Figure 5: UNICEF tents and Tzu Chi Foundation temporary classrooms (grey roof) were built in the San Joaquin elementary schoolyard in Palo.

\subsection{Support by international organization}

Many humanitarian organizations and educational organization support teams supported the affected area after Typhoon Haiyan. The Philippines Red Cross acted as an operational center for providing First Aid and blood supply and running mobile clinics for who those are not able to see doctors. International Red Cross teams specializing in health, IT, water and sanitation, logistics and relief worked in the affected area to facilitate recovery. Community-based 
activities were operated, psychosocial support activity was provided for children by the Japanese Red Cross Society [3], and the medical team of Doctors Without Borders (MSF) visited villages for medical care with their own medical equipment [4].

Education-based support was provided by different organizations. UNICEF and international NGOs such as Save the Children provided school supplies; the Samaritan's Purse provided food, sanitary goods, and building tools; and the Taiwanese NGO, Tzu Chi Foundation, built temporary classrooms on the schoolyards. Support from NGOs was voluntarily provided, and the advantages were unequally distributed; for example, schools along highways or coastal area received a variety of support, while schools invisible from the road received not even the support recognized by UNICEF as the most basic. Japan Platform Program provided the Kids Care program, which consisted of a mental care and social care class to encourage children to keep attending schools and to avoid potential poverty, as resulted in only Bisilig elementary school, Tanauan.

Most damaged schools were aided by ARAW, South Korea's biggest and oldest international campaign for humanitarian assistance, which rebuilt 67 buildings, including 37 schools, between January 3 and November 27, 2014. As NGOs provide early-stage relief goods, Korean military provides permanent infrastructural support for their mission. Additionally, individual support was also provided; only the San Joaquin elementary school in Palo experienced a Japanese individual donation of cash to cook and provide a meal to 500 students.

\section{Discussion}

All visited schools sustained severe damage, even far west inland from the coast. The causes of damage were strong winds, storm surge and river flood in riverside villages. Schools near the coast were washed out completely, such as Santa Cruz primary school. The engineering analysis of the damage will be reported separately [5-7].

Elementary schools play a central role in communities, not only for education but also as a safety function as evacuation centers. The topology of the affected areas in Tanauan, Palo and Tacloban is flat. Anibong elementary school in Tacloban is the only school that stands on a hill, approximately $12 \mathrm{~m} \mathrm{(38 \textrm {ft } )}$ above sea level. Therefore, elementary schools are not suitable as evacuation centers for coastal disasters such as tsunamis or storm surge. An evacuation education program by the Boy Scouts for students and the Department of Education for teachers was implemented in some schools; however, the program focused on earthquakes and fires.

Typhoons are common in this area; thus, developing evacuation drills for coastal disasters and related disasters, such as landslides, and enhancing resilience of communities for disaster reduction is imperative. It is our recommendation that the church could function as an evacuation center because the church is generally the highest building in the community. The students need 
to be structurally educated and the program materials and necessities made so that when another disaster strikes, the younger generations of today can face the disaster and overcome the challenges by strong will or with structured systems and tools.

\section{Acknowledgements}

This study was funded by a discretionary budget from the president of Tohoku University and the director of the International Research Institute of Disaster Science (IRIDeS), Tohoku University, and Tokio Marine and Nichido Fire Insurance Co., Ltd. We deeply thank the officers of the Planning Departments of the Municipality of Tanauan, Ms. Cecile Mae M. Ocado, Ms. Dayday M. De La Cruz and Mr. Jerome S. Fabre, who provided the geospatial data set and its attribute values and 2012 Tanauan Census data.

\section{References}

[1] Lum, T. \& Margesson, R., Typhoon Haiyan (Yolanda): U.S. and International Response to Philippines Disaster (7-5700_R43309), Congressional Research Service.

[2] Goonesekere, S. \& Alwis, R. S. A., UNICEF Working paper: Women's and children's rights in a human rights based approach to development. 2005, https://www.wcwonline.org/pdf/asia2007conf/Women's\%20and $\% 20$ Childre n's\%20Rights\%20in\%20a\%20Human\%20Rights\%20Based\%20Approach.p df.

[3] Japanese Red Cross Society, One Month on from Typhoon Haiyan, 2013, http://www.jrc.or.jp/english/relief/131209 001766.html.

[4] The Doctors Without Borders (Médecins Sans Frontières (MSF)), The Philippines: One year after typhoon Haiyan, 2014, http://www.doctorswithoutborders.org/sites/usa/files/attachments/typhoon haiyan one year accountability report final.pdf.

[5] Yi, C.J., Suppasri, A., Kure, S., Bricker, J. D., Mas, E., Quimpo, M. \& Yasuda, M., Storm surge mapping of typhoon Haiyan and its impact in Tanauan, Leyte, Philippines, International Journal of Disaster Risk Reduction, 2015 (in revision).

[6] Leelawat, N., Suppasri, A., Chravet, I., Yi, C., Watanabe, M., Bricker, J. D., Yasuda M. \& Imamura, F., Differentiation of wind and storm surge induced damage in case of the 2013 Super Typhoon Haiyan based on damaged school buildings data in Tanauan municipality, the Philippines, Coastal Engineering Journal (This issue), 2015 (under peer review).

[7] Suppasri, A., Yi, C., Leelawat, N., Watanabe, M., Bricker, J. D., Yasuda, M. \& Imamura, F., Field survey and analysis of school buildings damaged by Typhoon Haiyan's winds and storm surge, Journal of Japan Society of Civil Engineers, Ser. B2 (Coastal Engineering), 2015 (under peer review). 